\title{
Maternal satisfaction on postnatal and neonatal care of babies treated for neonatal sepsis in secondary and tertiary care hospitals of a district in Sri Lanka
}

\author{
Chintha Jayasinghe ${ }^{1}$ \& Chrishantha Abeysena $^{2 *}$ \\ ${ }^{1}$ Epidemiology Unit, Ministry of Health, Sri Lanka; ${ }^{2}$ Department of Public Health, Faculty of Medicine, \\ University of Kelaniya, Sri Lanka \\ *Correspondence: chrishanthaabeysena@yahoo.com (iD https://orcid.org/0000-0001-5456-8281
}

DOI: https://doi.org/10.4038/jccpsl.v26i1.8209

Received on 07 July 2019

Accepted on 05 October 2019

\begin{abstract}
Introduction: Patient satisfaction is considered to be a vital component in the evaluation of the quality of care.

Objectives: To describe the maternal satisfaction on care received by the neonates and mothers during their stay in the secondary and tertiary care hospitals in a district of Sri Lanka

Methods: This was a descriptive study conducted among 235 postpartum mothers of neonates who were treated for sepsis in the neonatal intensive care units. An interviewer-administered questionnaire was used to assess maternal satisfaction regarding the care received by the mothers (20 items) and neonates (20 items). The mothers were also requested to make suggestions for improvement. The questionnaire was administered on the day of discharge from the hospital. Overall satisfaction scores for maternal care and neonatal care were calculated separately and was considered satisfactory if it was more than $75 \%$ of the total score.

Results: The overall mean satisfaction score for maternal care was 84.2 (range 49-100) and for neonatal care, it was 94.0 (range 52-98). Majority of the mothers were satisfied with the maternal care ( $\mathrm{n}=208 ; 88.5 \%)$ and neonatal care ( $n=220 ; 93.6 \%)$. The majority were satisfied regarding the breastfeeding counselling ( $n=224 ; 93.3 \%$ ), information on the treatment their neonates received $(n=227 ; 94.6 \%)$ and investigations of the neonates $(n=196 ; 81.7 \%)$. A higher percentage also recommended the obstetric unit to others as a favourable place $(n=224 ; 93.3 \%)$ and preferred to return to the same unit for neonatal care for any future episode of illness (n=227; 94.6\%).
\end{abstract}

Conclusions: The overall maternal satisfaction regarding the neonatal and maternity care was high. There was a gap between the needs and provision of healthcare.

Key words: intensive care, neonatal, postnatal, quality, satisfaction, sepsis 


\section{Introduction}

Patient satisfaction is considered to be a vital component in the evaluation of the quality of healthcare (1). Therefore, maternal satisfaction towards healthcare can be used as a good proxy measure for assessing the quality of care provided for their neonates. The main concern of healthcare service providers is to deliver the best available medical services from a technical point of view (2). The social and humanities aspects of healthcare have also been much emphasized in relation to patient-centred approach. Patients, while expecting the best technical services, are also concerned about the manner in which the services are delivered as well as the setting in which they are provided (3-4). The dignity and other interpersonal aspects of the service is the vehicle by which technical care is implemented and on which its success depends (3). Parent satisfaction on healthcare was associated with the improvement in their children's clinical status and understanding of the information given by healthcare workers (5). Several studies have focused on maternal satisfaction on neonatal care (6-7). There is evidence that increasing knowledge on medical care results in parents being more confident about the sick child's situation and subsequently feeling more secure. Conversely, parental anxiety can have reverse effects resulting in fearful and anxious patients (8).

Although there has been delivery of free healthcare to every person in Sri Lanka by successive governments since independence, it is important to evaluate the satisfaction of service delivery from time to time. We have creditable health indices in comparison with other countries with relatively low per capita income (9). In an era where the public concern on social and humanities need is regarded equally important, patient satisfaction surveys are important to further enhance the quality of health services. While improving the satisfaction rarely creates a strain on the available scarce resources, dissatisfaction of the services could lead to poor utilization of health services. Only minimal finances are necessary to improve satisfaction on various components of the healthcare system. It is the awareness of the service providers that needs to be addressed in order to improve the way the patients are treated and the setting in which they are treated.

There had been an increasing emphasis on the use of patient satisfaction surveys to gather information providing consumer views, which can be used to influence policy and service development. In the public sector, quality measures function as a direct measure of accountability as well as providing information to hospitals about the areas for improvement. The objective of the study was to describe maternal satisfaction on care received by the neonates and mothers during their stay in the secondary and tertiary care hospitals in a district in Sri Lanka.

\section{Methods}

A descriptive cross-sectional study was conducted in four hospitals in the district of Gampaha, namely Colombo North Teaching Hospital (CNTH), District General Hospital Gampaha (DGHG), District General Hospital Negombo (DGHN) and the Base Hospital Wathupitiwala (BHW) from August 2010 to January 2011. The study setting included the hospitals where there are neonatal intensive care units (NICU). There are five NICUs. The study population comprised mothers with neonates diagnosed of sepsis. We recruited 240 mothers consecutively from the above hospitals during the study period. This was a component of a larger study (10).

Maternal satisfaction with various aspects of care provided through the government health services were assessed at the discharge of the neonates from the hospital. An interviewer-administered questionnaire (IAQ) was used for data collection. It consisted of two parts. One was on the socio-demographic, maternal and neonatal factors. Second was on the maternal satisfaction regarding the care received in the postnatal wards and the neonatal care in NICU. In addition, there were two open-ended questions where the participants were asked to give three recommendations to improve satisfaction regarding care provided to mothers and neonates.

The draft questionnaire was prepared by reviewing similar studies in local and international level (11-15). The original questionnaire was prepared in English and translated into Sinhala language and was discussed with an expert panel. The questionnaire included 20 items referring to the satisfaction of mothers on neonatal care; 20 items referring to the care received by mothers after admission to the hospital for delivery of the neonates; and a few items referring to the sociodemographic, maternal and neonatal factors. The 
satisfaction of mothers on neonatal care was categorized into five domains, namely the information they received regarding their neonate's illness; skills of the staff and the time they spent with the neonate; communication with mothers; kindness of the various categories of staff when providing services; and mothers' recommendation of the institution the child would stay in future admission. The satisfaction of mothers on maternal care was categorized into six domains. They were physical and sanitary facilities; diet and drinking water; kindness of staff; breastfeeding counselling; information and communication; and respect and recommendation of the institution for maternity care for future admissions. Each statement on satisfaction had a 5-point Likert scale ranging from 'highly satisfied', 'satisfied', 'neither satisfied nor dissatisfied', 'dissatisfied' and 'highly dissatisfied'. Marks were allocated from 5-1 according to the descending degree of satisfaction for each statement.

Assessment of content validity of the IAQ was carried out by an expert panel. All the experts agreed upon the appropriateness of content to measure the satisfaction of care, relevance in the local context, and appropriateness of the words used. The questionnaire was pre-tested at the Base Hospital Avissawella for feasibility and appropriateness. The reliability was assessed employing test re-test method by readministering the IAQ in 10 randomly selected mothers who participated in the study. Results of test re-test reliability of the selected variables were assessed using Kappa, showing a minimum score of 0.60 and good agreement.

All the mothers were asked in an open-ended question to offer three recommendations to improve the maternal and neonatal care in the hospitals. The answers given were clustered under the following categories for neonatal care: to improve the facilities which are not currently available, to further improve of currently available services and to improve the physical facilities. The recommendations for improving maternal care were categorized as follows: to improve sanitary facilities such as toilet facilities and (increase) the number of dust bins, to improve service facilities such as increasing the availability of essential equipment and the availability of medicine like prostaglandin pessaries, and to improve non sanitary physical facilities such as mosquito nets and adequate space for breastfeeding.
Two pre-intern medical officers were trained as data collectors. Informed written consent was obtained from all the participants.

\section{Data analysis}

Data entry and analysis were done by using Statistical Package for Social Sciences (SPSS) version 16. The individual item satisfaction was calculated as a proportion of each item of satisfaction. The answers of 'highly satisfied' and 'satisfied' were amalgamated as 'satisfied' for this purpose. Answers of 'neither satisfied nor dissatisfied', 'dissatisfied' and 'highly dissatisfied' were amalgamated as 'dissatisfied'. Overall satisfaction score was calculated and more than $75 \%$ was taken as satisfaction.

\section{Results}

Five mothers did not respond to the questionnaire, giving a response rate of $98 \%$. The largest number of neonatal sepsis was reported from the CNTH $(n=72$; $30.0 \%)$; DGHG $(n=73 ; 30.3 \%)$; DGHN $(n=54$; $22.5 \%)$ and BHW $(n=36 ; 15.2 \%)$. Distribution of maternal and neonatal factors are described in Table 1. The highest proportion $(n=89 ; 37.1 \%)$ of study participants belonged to 26-30 years of age; were Sinhalese in ethnicity ( $\mathrm{n}=224$; 93.3\%); and had passed General Certificate of Education (GCE) Ordinary/ Level $(\mathrm{n}=103 ; 42.9 \%)$.

\section{Maternal satisfaction on maternal care}

The satisfaction on sleeping facilities and the toilet facilities provided by the hospital was stated by $78.4 \%$ and $69.9 \%$ of mothers, respectively. Of them, $91.2 \%$ had not taken the diet supplied by the hospital. Those who took the diet from the hospital were 100\% satisfied with it. The mothers who were entitled for a diabetic diet or any other specified diet had taken the hospital diet. Only 8.3\% mothers had taken drinking water provided by the hospital and all of them were satisfied with it. A majority of mothers (93.3\%) were satisfied regarding the breastfeeding counselling and management (Table 2). The satisfaction of mothers on the kindness of the consultant was $92.5 \%$, medical officers $93.3 \%$, nursing officers $91.6 \%$ and minor staff $86.7 \%$. A majority (93.3\%) of mothers were satisfied with their obstetric unit and they recommended the same unit for others as a favourable place (Table 2). 
The overall mean satisfaction score for maternal care was 84.2 (range 49-100). The vast majority $(n=208$; $88.5 \%$ ) of the mothers were satisfied with the maternal care received during their hospital stay.

\section{Maternal satisfaction on neonatal care}

A majority (94.6\%) of mothers were satisfied with the treatment their neonates received, whereas $81.7 \%$ mothers were satisfied with the information given on investigations. Practice of the staff of introducing themselves to the patients is a new concept in Sri Lanka and $95.8 \%$ of mothers were dissatisfied with it. The satisfaction regarding the support given to the baby and the mother when needed was 93.8\% and 95.4\%, respectively. The communication domain also received high scores by a majority of the mothers; for opportunity to ask questions (95.4\%) and understanding of explanations given by the staff (90.4\%). Hundred and ninety-three (80.4\%) mothers were satisfied with the kindness of consultant and junior medical officers, nursing staff and minor staff (90.0\%, 94.0\% and 92.9\%, respectively). The majority of mothers (95.8\%) recommended admission of another child to the same unit, whereas $94.6 \%$ of them preferred to return to the same unit for future illness (Table 3 ). The overall median satisfaction score for neonatal care was 94.0 (range 52-98). The vast majority $(n=220 ; 93.6 \%)$ of the mothers were satisfied with the neonatal care.

Table 1. Distribution of maternal and neonatal characteristics $(\mathrm{N}=235)$

\begin{tabular}{|c|c|c|}
\hline Characteristics & No. & $\%$ \\
\hline \multicolumn{3}{|l|}{ Type of the hospital } \\
\hline Tertiary care & 90 & 38.3 \\
\hline Secondary care & 145 & 61.7 \\
\hline \multicolumn{3}{|l|}{ Presence of bad obstetric history } \\
\hline Present & 55 & 23.4 \\
\hline Absent & 180 & 76.6 \\
\hline \multicolumn{3}{|l|}{ Mode of delivery of the baby } \\
\hline Normal vaginal delivery & 124 & 21.8 \\
\hline Instrumental delivery or caesarean section & 111 & 26.1 \\
\hline \multicolumn{3}{|l|}{ Number of days in hospital } \\
\hline$<10$ days & 103 & 52.7 \\
\hline$\geq 10$ days & 132 & 47.3 \\
\hline \multicolumn{3}{|l|}{ Maturity of the neonate } \\
\hline$\geq 36$ weeks & 189 & 81.1 \\
\hline$<36$ weeks & 44 & 18.9 \\
\hline \multicolumn{3}{|l|}{ Sex of the neonate } \\
\hline Male & 34 & 14.5 \\
\hline Female & 101 & 85.5 \\
\hline \multicolumn{3}{|l|}{ Birth weight of baby } \\
\hline$\geq 2500 \mathrm{~g}$ & 162 & 69.0 \\
\hline$<2500 \mathrm{~g}$ & 73 & 31.0 \\
\hline \multicolumn{3}{|l|}{ Age of onset of the sepsis of neonates } \\
\hline Early onset $<72$ hours & 160 & 68.0 \\
\hline Late onset $\geq 72$ hours & 75 & 32.0 \\
\hline
\end{tabular}


Table 2. Maternal satisfaction on the services received by mothers during hospital stay $(\mathrm{N}=235)$

\section{Description of the services}

\section{Satisfied}

Dissatisfied

\begin{tabular}{lcccc} 
& No. & \% & No. & \% \\
\hline Physical and sanitary facilities & & & & \\
- Sleeping facilities provided & 188 & 78.4 & 67.6 & 28.3 \\
- Toilet facilities provided & 167 & 69.9 & 68 & 17.1 \\
- Cleanliness of the floor of the wards & 194 & 80.8 & 71 & 22.9 \\
- Other facilities provided & 180 & 75.0 & 55 & 28 \\
- Physical appearance of the wards & 207 & 86.3 & & 21.7
\end{tabular}

Food provided by the hospital

- Diet provided

$\begin{array}{llll}16^{1} & 6.7 & 0 & 0.0\end{array}$

- Drinking water

$20^{2}$

8.3

0.0

Kindness of staff

- Consultant

\begin{tabular}{llll}
222 & 92.5 & 13 & 5.4 \\
224 & 93.3 & 11 & 3.8 \\
220 & 91.6 & 13 & 6.0 \\
229 & 95.5 & 6 & 2.7 \\
208 & 86.7 & 27 & 13.3 \\
\hline
\end{tabular}

Breast feeding counselling

- Explanation on breast feeding

224

93.3

11

3.8

\section{Information and communication}

- Opportunity to ask questions

$\begin{array}{llll}228 & 95.4 & 7 & 3.1 \\ 219 & 913 & 14 & \end{array}$

- Understanding of explanations given

- Time spent on explanations

- Reassurance, counselling and management

216

90.8

18

\section{Respect and recommendation}

- Respect shown towards mother

$\begin{array}{llll}230 & 95.8 & 5 & 2.3 \\ 224 & 93.3 & 11 & 3.8 \\ 225 & 93.8 & 10 & 3.5\end{array}$

- Recommendation to another mother as a favourable place

225

93.8

${ }^{1} 219$ mothers did not take diet provided by the hospital; ${ }^{2} 214$ mothers did not take water provided by the hospital 
Table 3. Maternal satisfaction on services received by/provided to neonates during hospital stay $(\mathrm{N}=235)$

\begin{tabular}{|c|c|c|c|c|}
\hline \multirow[t]{2}{*}{ Description of the services } & \multicolumn{2}{|c|}{ Satisfied } & \multicolumn{2}{|c|}{ Dissatisfied } \\
\hline & No. & $\%$ & No. & $\%$ \\
\hline \multicolumn{5}{|l|}{ Information regarding neonates } \\
\hline - Illness & 203 & 84.6 & 32 & 13.3 \\
\hline - Investigations & 196 & 81.7 & 39 & 15.2 \\
\hline - Treatment & 205 & 85.2 & 30 & 12.4 \\
\hline - Treatment received & 227 & 94.6 & 8 & 3.3 \\
\hline \multicolumn{5}{|l|}{ Skills and time spent } \\
\hline - Confidence and competence/skills of staff & 212 & 88.4 & 23 & 9.1 \\
\hline - Counselling, explanation and reassurance & 215 & 89.3 & 23 & 8.4 \\
\hline - Introduction of staff by themselves & 5 & 2.1 & 230 & 95.8 \\
\hline - Staff willingness to help when neonate needed & 223 & 92.9 & 12 & 5 \\
\hline - Love and respect towards neonate & 225 & 93.8 & 10 & 3.7 \\
\hline - Staff willingness to help when mother needed & 227 & 94.6 & 8 & 3.3 \\
\hline - Time spent to answer questions & 215 & 89.6 & 20 & 8.3 \\
\hline \multicolumn{5}{|l|}{ Communication } \\
\hline - Opportunity to ask questions & 227 & 94.5 & 8 & 3.3 \\
\hline - Understanding of explanations & 217 & 90.4 & 18 & 7.5 \\
\hline \multicolumn{5}{|l|}{ Courtesy of staff } \\
\hline - Consultant & 193 & 80.4 & 42 & 17.6 \\
\hline - Medical officer & 216 & 90.0 & 19 & 8.6 \\
\hline - Nursing officer & 226 & 94.0 & 9 & 3.5 \\
\hline - Minor staff & 222 & 92.9 & 13 & 4.9 \\
\hline \multicolumn{5}{|l|}{ Respect and recommendations } \\
\hline - Love and respect towards mother & 222 & 92.6 & 13 & 5.4 \\
\hline - Return to same institution for the next episode & & & & \\
\hline of illness of my child & 227 & 94.6 & 8 & 3.3 \\
\hline - Recommendation for another child as a favourable place & 225 & 93.8 & 10 & 4.1 \\
\hline
\end{tabular}

Five mothers did not respond

\section{Recommendations of the mothers to improve neonatal care in the hospitals}

Of the mothers ( $n=106 ; 44.2 \%)$ of babies with neonatal sepsis, the majority mentioned that the facilities for investigations should be improved as some investigations were done at private sector laboratories (Table 4). For example, almost all C-reactive protein tests were done at private sector laboratories. A large proportion of mothers $(\mathrm{n}=73 ; 30.4 \%)$ recommended that the availability of medicine be increased as they had to buy some of the antibiotics out of pocket. Thirtythree mothers (13.8\%) suggested that the facilities for fathers to stay with their neonates for a longer period of time should be increased. Ten mothers (4.1\%) pointed out the need for more facilities for low birth weight/ premature neonates while eight (3.3\%) stated 
that there should be more facilities to obtain information regarding the neonate's condition (keep a receptionist during visiting hours). The majority of mothers ( $n=84$; $35 \%$ ) expressed the need for regular training for infection control practices and providing health education. Forty-four mothers suggested increasing the number of junior medical officers. Five percent $(n=12)$ of the mothers suggested proper training of medical students before handling mothers and babies (Table 4). A large proportion of mothers $(n=104$; 43.4\%) mentioned that the NICU is not situated close to the postnatal ward and that they found it difficult to walk this distance from the postnatal wards. Fortyeight mothers (20\%) suggested establishing motherbaby units to keep mother and baby together when they are sick (Table 4).

Table 4. Recommendations of mothers to improve the quality of neonatal care $(\mathrm{N}=235)$

\section{Recommendations}

\section{Introducing currently non-available facilities}

- Improve the facilities for investigations like C-reactive protein

- Increase facilities for low birth weight/ premature neonates No. $\%$

- Increase the facilities to get information regarding the neonate's condition (keep a receptionist during visiting hours)

Improve the currently available services

- Regular mechanism for mothers to train on infection control / at least on hand washing

- Increase availability of medical officers

- Staff should get more precautions on infection control

- Small hospitals should develop more for deliveries

- Medical students should train before handling mothers and babies

- Special training to staff on premature and low birth weight

- Increase number of minor staff in the labour room

\section{Improve physical facilities}

- Arrange to reduce the distance to NICU from postnatal wards or provide more beds for postnatal mothers closer to NICU 104

- Keep mother and baby together as far as possible/improve mother baby units

- Establish a dining area/room for mothers

- Arrange the sitting space for feeding mothers

- Evacuate the mosquito breeding sites from the hospital

- Improve the cleanliness of NICU

- Limit visitors to NICU/ mother baby units

- Supply of mosquito nets for mothers in the NICU room 
A large proportion (35.4\%) of mothers recommended that the cleanliness of toilets be improved; and the number of toilets be increased, whereas $20.4 \%$ of mothers recommended the improvement of the cleanliness of the postnatal wards. The majority of mothers (33.3\%) recommended that the availability of medicine and equipment like cannulas be increased. Sixty-seven (27.9\%) mothers suggested training the minor staff regarding patient care. Fifty mothers (27.9\%) recommended that the number of visits to the postnatal wards by the consultants should be improved. Seventy-five mothers (31.3\%) mentioned being pestered by the stray dogs and cats in the wards. A large proportion of mothers (22.9\%) also mentioned that the number of beds were not enough in the postnatal wards (Table 5).

Table 5. Recommendations of mothers to improve quality of maternal care $(\mathrm{N}=\mathbf{2 3 5})$

\begin{tabular}{lcc}
\hline Recommendations & No. & \% \\
\hline To improve sanitary facilities & 85 & 36.1 \\
- Improve the cleanliness of toilets / number of toilets & 49 & 20.8 \\
- Clean the postnatal wards more frequently & 44 & 18.7 \\
- Increase the number of dust bins in the toilets & 43 & 17.3 \\
- Regular training of mothers on discarding sanitary pads & 10 & 4.2 \\
- Increase number of commodes / showers & 4 & 1.7 \\
- Non-response & 4
\end{tabular}

\section{Improve the service facilities}

- Increase availability of essential equipment like cannulas/urinary catheters $\quad 80 \quad 34.0$

- $\quad$ Train minor staff to care for patients $\quad 67 \quad 28.5$

- Regular visits to postnatal section by consultants to increase care of postnatal mothers $\quad 50 \quad 21.3$

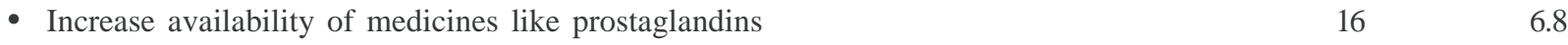

- Non-response $\quad 4 \quad 1.3$

\section{To improve non sanitary physical facilities}

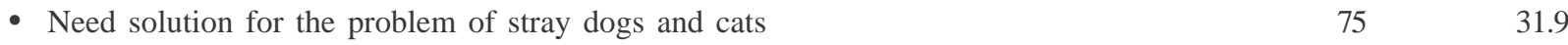

- Insufficient number of beds in the wards $\quad 55 \quad 23.4$

- Postnatal wards/ mother and baby wards are too warm $\quad 43 \quad 18.3$

- Flies are all over the wards $\quad 19 \quad 8.0$

- Mosquito problems and the supply of mosquito nets 114.7

- $\quad$ Breast feeding place is not adequate/privacy is not maintained $\quad 11 \quad 4.7$

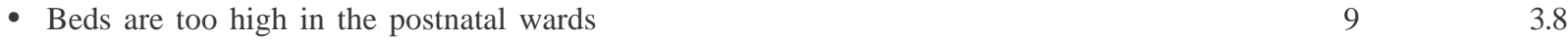

- Non-response $\quad 10 \quad 10 \quad 4.2$ 


\section{Discussion}

\section{Maternal satisfaction for maternal care}

We found $88.5 \%$ of the mothers were satisfied with the care provided to them in obstetric wards. One Sri Lankan study (12) found that $98.4 \%$ of mothers were satisfied with the total maternity care provided by the primary care hospitals in Kalutara District. Another study (16) conducted in Nepal reported that $89.9 \%$ of mothers were satisfied with the delivery of service while in Ethiopia, it was $87.2 \%$ (17).

In the present study, the satisfaction of mothers regarding toilet facilities were $69.9 \%$. A Sri Lankan study (12) reported that $76.2 \%$ of mothers were satisfied with the sanitary facilities provided during their hospital stay while another study (13) found that only $35 \%$ of mothers were satisfied with the toilets and water supply of the maternity wards in Puttalam District. A study conducted in Nepal reported that 74\% mothers were satisfied with the cleanliness of toilets (16). The proportion of mothers satisfied with the cleanliness of the maternity wards was $86.3 \%$ in the present study and it had been $70.4 \%$ in Puttalam District and 96.8\% in Kalutara District. The present study revealed that satisfaction of the physical appearance of wards was $86.3 \%$ and according to another study (13), it was $28.7 \%$. Another study in Serbia (18) found that maternal satisfaction on sanitary facilities was $44 \%$. The differences in satisfaction between local studies regarding cleaning, appearances and cleanliness of the wards may be due to the current policy of sanitation in health institutions. In the past, maintenance of cleanliness of government hospitals was done by government sanitary workers. At present, this is done by private sector cleaning services at almost all the government hospitals. This may be the reason for improvement of satisfaction on sanitation and cleaning than the earlier studies.

Ninety one percent (91.2\%) of mothers were satisfied with the level of communication of healthcare staff. One study conducted in primary care hospitals (12) reported that $99.45 \%$ of the mothers discussed and communicated their problems with the midwives. In the present study, with regard to the opportunity to ask questions, $93.4 \%$ responded positively. In tertiary care hospitals, the staff is usually busy and there is a considerable workload whereas in the primary care setting they may have the time to talk to the patients as the number of patients may be less.

Maternal satisfaction regarding breastfeeding promotion and counselling in the present study was 93.3\%. A study (13) conducted in 2004 reported that the assistance given to breastfeeding mothers was $12.3 \%$, indicating poor satisfaction. This sizeable difference between the two studies may be due to the number of training programmes carried out by the Ministry of Health on breastfeeding promotion and counselling for midwives and nursing officers during the previous years with the implementation of the policy on exclusive breastfeeding for six months. In Serbia, a study (18) found that $65.4 \%$ of mothers were satisfied regarding breastfeeding assistance and counselling. In Nepal, 81.4\% of mothers were satisfied about the information given on breastfeeding (16).

Considering the kindness of health staff, the mothers' satisfaction regarding consultants were 92.5\%, doctors 93.6\%, nursing officers 92.5\%, midwives $95.8 \%$ and other staff $86.7 \%$. In Greece, a study (5) found the politeness of doctors and nurses to be $94.6 \%$ and $89.3 \%$, respectively.

\section{Maternal satisfaction on neonatal care}

We found that $93.6 \%$ of the mothers were highly satisfied with the neonatal care received. A review (19) also concluded that a vast majority of the parents were highly satisfied with the care received in the NICU. In contrast, one study (20) concluded that the overall level of maternal satisfaction was sub-optimal with the care received in an NICU.

Eighty four percent of mothers were satisfied with the information received regarding their neonate's illness, investigations and treatment. In Greece, a study (5) revealed the maternal satisfaction on provision of information about child's illness to be $94.8 \%$; understanding of given information was $85.4 \%$; and the treatment received by neonates was $94.6 \%$. According to another study (21), maternal satisfaction on the treatment they received in the tertiary care hospital in Sri Lanka was $91.1 \%$. A study conducted in India (22) also reported that $56 \%$ of the parents were completely satisfied with information given by the staff. 
A vast majority of the mothers (88.4\%) were satisfied with the competencies of the healthcare staff. One study (22) reported that $82 \%$ of parents were completely satisfied with the care provided by the staff. However, the healthcare staff introducing themselves before corresponding with the patients is not usually practiced in Sri Lanka. Therefore, the satisfaction on that item was indicated as a highly dissatisfied (92\%). One study (16) reported that $85 \%$ of mothers were satisfied with the warm welcome given by the staff upon admission.

Satisfaction with the opportunity to ask questions when they provide paediatric care in the present study was $94.5 \%$. One study (13) found that $47.9 \%$ of mothers expressed their satisfaction regarding the opportunity given to them to clarify their doubts regarding the care of the newborn which was a low figure compared to other studies. A study (22) conducted in India reported that $70 \%$ of the parents were completely satisfied with the information given during the time of discharge.

A higher proportion of mothers were satisfied with the kindness of staff and comprised $80.4 \%, 90.0 \%$, $94.6 \%$ and $92.9 \%$ of consultants, medical officers, nursing officers and minor staff, respectively. Another Sri Lankan study (13) found that it was $95.1 \%$ for medical officers and $92.6 \%$ for nursing officers in Puttalam District. De Silva (21) revealed that $98.6 \%$ of mothers were satisfied with the doctor's attitude towards their sick child. In contrast, an Indian study (22) demonstrated that the majority of the parents were not completely satisfied with the empathic attitudes of the staff. Even in England, the mothers were more content when their neonates were examined by midwives rather than by senior house officers (23). In the present study, 94.6\% mothers said that they would come back to the same institution for any future episodes of illness of their children. This showed the confidence the clients had on the government health services. Further according to De Silva et al. (1996), $77 \%$ of mothers mentioned that they would come back to the same institution for any future illness (21). However, the comparison based on a composite score of satisfaction is not appropriate, as the number of items for assessing satisfaction, the scope of the items, scoring methods and determining the cut-off level to define satisfaction are different across the studies.
Moreover, patient's expectation had been considered as primary in determining the level of satisfaction. Patients with lower expectations were more easily satisfied (24).

Measuring the satisfaction on care is a challenging task as people tend to give positive responses to questions that were asked about their views on medical care. Brown et al. (1994) in Australia expressed (25) that in surveys, more than $80 \%$ state that they are satisfied when questioned and state the same for overall rating of care as well. As these interviews were conducted in the hospital premises, mothers may have reported more positive perceptions of the services and greater satisfaction than they actually felt. This is because they are reluctant to express dissatisfaction to a certain degree. This in turn leads to a degree of underreporting of deficiencies and dissatisfaction regarding care. This issue was highlighted by the previous authors (23) and this underreporting was minimized in the present study by carrying out an exit interview. Furthermore, interviews were carried out in a place where there was no access to healthcare workers. We were also unable to assess the associated factors for satisfaction of the mothers as the vast majority of the mothers in our study were satisfied, the sample size for the dissatisfied group was not adequate for statistical analysis.

According to our study, there is a gap between the needs and available facilities. Most of the mothers stated the need for drugs and laboratory facilities for the proper management of the neonates. In addition, welfare facilities including beds for mothers are also essential for maintaining physical and mental wellbeing of the mother. Medical administrators should seriously consider these factors for improving the quality of neonatal care.

\section{Conclusions \& Recommendations}

The overall maternal satisfaction regarding the neonatal care and maternity care was high. There was a gap between the needs and provisions of healthcare in relation to technical and administrative concerns. New customer service strategies for better public relations are to be introduced to government healthcare workers. Short training courses for the undergraduates and nursing students as well as in-service training for 
all categories of staff regarding soft skills such as communication and empathy are also to be introduced.

\section{Public Health Implications}

The overall maternal satisfaction regarding the neonatal care and maternity care was high. There was a gap between the needs and provisions of healthcare in relation to technical and administrative concerns. Obtaining regular feedback from the mothers and activate accordingly may improve the gaps in provision of healthcare. Short training courses for the undergraduates and as well as in-service training for all categories of staff regarding soft skills are also to be introduced.

\section{Author Declarations}

Competing interests: The authors declare that they have no competing interests.

Ethics approval and consent to participate: Ethical clearance was obtained from the Ethics Review Committee of the Faculty of Medicine, University of Kelaniya. Administrative clearance for the data collection was obtained from the Regional Director of Health Services of Gampaha District and directors of the relevant hospitals prior to data collection. Prior approval was obtained from the consultants in charge of the Gynaecological, Paediatric, and postnatal wards, and the NICU.

\section{Funding: Self-funded}

Acknowledgement: The funding body is gratefully acknowledged by the authors.

Author contributions: CJ participated in the design of the study, coordinated data collection, performed the statistical analysis and helped to draft the manuscript. CA participated in the design of the study, performed the statistical analysis, interpreted the data and drafted the first version of the manuscript. Both authors read and approved the final manuscript.

\section{References}

1. Goodman P, Mackey MC, Tavakoli AS. Factors related to childbirth satisfaction. Journal of Advanced Nursing 2004; 46(2): 212-219.

2. Department of Child and Adolescent Health and Development (CAH). Handbook: IMCI Integrated Management of Childhood Illness (WHO/FCH/CAH/ 00.12). Geneva: World Health Organization, 2005. Available from: https://apps.who.int/iris/handle/10665/ 42939.

3. Donabedian A. The quality care, how can it be assessed? Journal of American Medical Association 1988; 260: 1743-1748.

4. Emmanuel EJ \& Emmanuel LL. What is accountability in health care? Annals of Internal Medicine 1996; 124 : 229-239.

5. Matziou V, Boutopoulou B, Chrysostomou A, Vlachioti E, Mantziou T, Petsios K. Parent's satisfaction concerning their child's hospital care. Japan Journal of Nursing Science 2011; 8(2): 163-173.

6. Conner JM, Nelson EC. Neonatal intensive care: satisfaction measured from a parent's perspective. Paediatrics 1999; 103: 336-349.

7. Saigal S, Stoskopf BI, Feeny D. Differences in preferences for neonatal outcomes among health care professionals, parents and adolescent. Journal of American Medical Association 1999; 281: 1991-1997.

8. Edwinson M, Ambjomsson E, Ekman R. Psychologic preparation programme for children undergoing acute appendectomy. Paediatrics 1998; 82(1): 30-36.

9. Medical Statistics Unit. Annual Health Statistics 2009/ 2010. Colombo: Ministry of Health Care and Nutrition, 2011.

10. Jayasinghe DUCJ. Neonatal sepsis: risk factors, effect on maternal psychological status, selected preventive care practices among care providers and maternal satisfaction with care in hospitals of Gampaha District. MD Thesis (Community Medicine). Colombo: Post Graduate Institute of Medicine, 2014.

11. Draper M, Cohen P, Buchan H. Seeking consumer views: What use are results of hospital patient satisfaction survey? International Journal for Quality of Health Care. 2001; 13(6): 463-468.

12. Goonewardena CSE. Selected aspect of quality of intrapartum and postpartum care at primary care level institution in the Kalutara District and intervention to improve care. MD Thesis (Community Medicine). Colombo: Post Graduate Institute of Medicine, 2001. 
13. Senarath LDJU. Essential newborn care services in a district of Sri Lanka and the effectiveness of an intervention to improve services. MD Thesis (Community Medicine). Colombo: Post Graduate Institute of Medicine, 2004.

14. Ygge BM \& Arnetz J. Quality of paediatric care: application and validation of an instrument for measuring parent satisfaction with hospital care. International Journal for Quality in Health Care 2001; 13(1): 33-43.

15. Waldenstrom U, Rudman A, Hildingsson I. Intrapartum and postpartum care in Sweden; women's opinions and risk factors for not being satisfied. Acta Obstetric Gynaecology 2006; 85: 551-560.

16. Panth A \& Praveena Kafle P. Maternal satisfaction on delivery service among postnatal mothers in a government hospital, Mid-Western Nepal Asha. Obstetrics and Gynaecology International 2018; Article ID 4530161. https://doi.org/10.1155/2018/ 4530161.

17. Agumasie M, Yohannes Kassa Z, Abegaz T. Maternal satisfaction and associated factors on delivery care service in Hawassa City Public Hospitals, South Ethiopia. Gynecology \&Obstetrics 2018; 8: 473.

18. Mategic B, Mlicevic MS, Vasic V, Djilanovic B. 2014. Maternal satisfaction with organized perinatal care in Serbian public hospitals. BMC Pregnancy and Childbirth 2014; 14: 14.
19. Butt ML, McGrath JM, Samra H, Gupta R. An Integrative Review of Parent satisfaction with care provided in the neonatal intensive care unit. Journal of Obstetric, Gynecologic \& Neonatal Nursing 2013; 42(1): 105-120.

20. Mekonnen WN \& Desalegn AM. Quality of service and associated factors in neonatal intensive care unit at Debre Berhan Referral Hospital, Debre Berhan Ethiopia: a cross-sectional study. Medical Journal of Dr DY Patil Vidyapeeth 2018; 11: 412-9.

21. De Silva KSH \& Dharmage SC. Assessment of client satisfaction in a paediatric ward. Ceylon Medical Journal 1996; 41(4); 148-150.

22. Sankar V, Batra P, Saroha M, Sadiza J. Parental satisfaction in the traditional system of neonatal intensive care unit services in a public sector hospital in North India. The South African Journal of Child Health 2017; 11(1): 54-57.

23. Wolk D, Daves S, Hayes I, Townsend J, Tomlin M. Routine examination of the newborn and maternal satisfaction: a randomized controlled trial. Archives of Disease in Childhood - Foetal Neonatal Edition 2002; 86(3): 155F-160.

24. Sitzia J \& Wood N. Patient's satisfaction: a review of issues and concepts. Journal of Social Science and Medicine 1997; 45(12): 1829-1843.

25. Brown S, Lumley J, Small R, Astbury J. Missing voices: the experiences of motherhood. Melbourne: Oxford University Press, 1995. 